\title{
EMPRESAS Y EMPRESARIOS ESPAÑOLES EN LA EXPORTACIÓN DE ACEITE DE OLIVA, 1900-1936. ESPECIAL REFERENCIA AL MERCADO NORUEGO DE CONSERVAS DE PESCADO *
}

\author{
SALVADOR HERNÁNDEZ ARMENTEROS \\ Universidad de Granada
}

\section{RESUMEN}

El avance de la revolución industrial supuso la pérdida de gran parte de los mercados tradicionales del aceite de oliva español, sin embargo, abrió otras posibilidades, otros mercados, que hasta ese momento eran desconocidos 0 de una estrechez que los hacía despreciables para dicha industria. Este es el caso de las conservas de pescado, entre cuyos inputs el aceite de oliva ocupó un lugar de gran importancia. Este trabajo tiene un triple objetivo: en primer lugar, analizar el comportamiento del aceite de oliva español en este mercado, centrando la atención en la industria conservera noruega, en segundo lugar, valorar el significado de las empresas y regiones que participan, en tercer lugar, comparar las exportaciones a este país, con las exportaciones a los mercados más importantes para el aceite de oliva español.

\section{ABSTRACT}

Industrial Revolution advance supposed the loss of a great part of traditional olive oil markets, however it caused some other possibilities, other markets, that up to that moment, the were unknown or the had such a small size that they were not considerable for this industry. This is the case of tinned fish, where olive oil was one of the most important inputs. This work

$N$. de E.: Fecha de recepción en la Revista de Historia Económica: enero, 2000

el Consejo de Redacción: junio, 2001.

mititud a Manuel Martín Rodríguez, a Juan Francisco Zambrana Pineda y a los dos evaluadores anónimos solicitados por la $R H E$ por sus observaciones $y$ sugerencias. 
has the following aims: first, to analyse the behaviour of Spanish olive oil in this market, paying attention to Norwegian tinned industry; second, to value the meaning of the companies and regions that take part; third, to compare the exports to this country with the exports to more important markets for Spanish olive oil.

\section{INTRODUCCIÓN}

El olivar y su producto principal, el aceite de oliva, ha sido, y continúa siendo, uno de los sectores de mayor importancia del complejo agroalimentario español. Su evolución, desde la primera gran expansión en las décadas centrales del siglo XIX, a finales del siglo $\mathrm{xx}$, ha merecido la atención de un gran número de investigadores que han centrado su interés, fundamentalmente, en los procesos de modernización del cultivo y de la industria aceitera ${ }^{1}$. Por otro lado, el fuerte peso que el aceite de oliva ha tenido tradicionalmente en la balanza comercial española, y el decisivo papel que el mercado exterior ha jugado en la evolución de este sector, han propiciado que hoy podamos contar con numerosos trabajos que han estudiado el comportamiento de la exportación del aceite de oliva.

Las características de la demanda internacional del aceite de oliva en las décadas centrales del siglo XIX, la situación del aceite de oliva español para satisfacerla y su aportación a la balanza comercial española, han sido tratadas en trabajos como los de Prados (1982 y 1988), Garrabou y Sanz (1985), el GEHR (1988) o Zambrana (1987). Los cambios que se produjeron en el último tercio del siglo XIX en los usos del aceite de oliva en el mercado internacional, la pérdida de sus mercados tradicionales, la necesidad de penetrar en otros nuevos y su incidencia en la superación de la denominada crisis agraria finisecular, han sido considerados, asimismo, por Gallego y Pinilla (1996), Pinilla (1995), Prados (1983 y 1991), Simpson (1992 y 1997) y Zambrana (1987). Por último, el avance de las exportaciones españolas en relación con sus principales competidores, Francia e Italia, y con el resto de los países de la cuenca mediterránea productores de aceite de oliva, están siendo tratados en una serie de interesantes trabajos que están apareciendo en los últimos años, entre los que cabe mencionar los de Federico (1992), Tena (1992) o Ramón (1997 y 2000).

${ }^{1}$ Entre los numerosos trabajos publicados en torno a esta cuestión, cabe destacar entre los publicados en los últimos años: GEHR (1988), J. I. Jiménez Blanco (1986), A. Parejo y Fco. Zambrana (1994), J. Simpson (1997), Fco. Zambrana (1987) (1999), S. Zapata (1986). 
Pese a todo, es en el campo de la comercialización donde aún quedan más incógnitas por desvelar. La profundización en la importancia y las características de los distintos mercados, las empresas que intervinieron en esta actividad, el origen del empresariado y capital que las pusieron en funcionamiento, o la situación relativa de la exportación española en cada uno de estos mercados, son parcelas que aconsejan un mayor esfuerzo investigador. En este ámbito se pretende enmarcar el presente trabajo.

Su objeto es adentrarse en una de las nuevas oportunidades que la revolución industrial ofreció al sector aceitero, la industria de conservas de pescado, entre cuyos inputs el aceite de oliva ocupó un lugar de gran importancia. Las características y exigencias de este nuevo mercado, y la respuesta dada por el sector aceitero español con relación a los otros grandes países exportadores, será la primera cuestión a tratar. En segundo lugar, nos aproximaremos a las empresas españolas que protagonizaron esta expansión, a su localización en las diferentes regiones productoras y a su nivel de especialización en este mercado. En tercer lugar, situaremos esta demanda en el conjunto de la actividad exportadora española de aceite de oliva, valorando los principales mercados, las empresas y regiones españolas que estuvieron presentes en ellos.

Para alcanzar estos objetivos, Noruega presenta unas características singularmente apropiadas. La importancia de la industria conservera en este país ${ }^{2}$ y el hecho de que sus empresas consideraran el aceite de oliva como el mejor conservante, y la riqueza de las fuentes, nos va a permitir un adecuado seguimiento de las exportaciones. Además la práctica totalidad de las importaciones de aceite de oliva de este país se dirigieron al sector conservero, esto nos permitirá disponer de un mercado único, sin otras demandas que pudieran interferir en el análisis del objeto de estudio ${ }^{3}$. Por otro lado, la juventud de la industria conservera noruega y su desconocimiento inicial del complejo sector del aceite de oliva, hizo que el suministro de este input estuviera durante años en manos de los expor-

${ }^{2}$ A mediados de los años cuarenta, tras la Segunda Guerra Mundial, la industria conservera noruega era, por su volumen de producción, la segunda del mundo, tras los EE UU y la primera respecto al volumen de exportación. La Industria Conservera (1947), octubre-noviembre, p. 10.

Las dificultades para el estudio del consumo de aceite de oliva en la industria conservera de otros paises destacados en esta actividad son difíciles de salvar. En los más importantes - España, EE UU, Portugal- se importa, en grandes envases, un volumen importante de aceite de oliva destinado, junto a las conservas de pescado, a otros usos, desde el consumo de boca, a la repostería, pasando por la industria del refino y posterior envasado y comercialización -EE UU - o exportación - Portugal y España-, que hacen muy difícil cuantificar este nuevo mercado. 
tadores de los diferentes países productores, quedándole sólo a los conserveros noruegos la posibilidad de controlar la calidad de los aceites importados y evitar los fraudes.

\section{EL ACEITE DE OLIVA EN LA INDUSTRIA CONSERVERA MODERNA. LA INDUSTRIA NORUEGA DE CONSERVAS DE PESCADO EN EL PRIMER TERCIO DEL SIGLO XX}

Pese a que la posibilidad de conservar los alimentos mediante la esterilización se conocía desde finales del siglo XviI ${ }^{4}$, su utilización industrial a gran escala no comenzó hasta mediados del siglo $\mathrm{xIX}^{5}$. Fue la industria francesa la que tomó la iniciativa ${ }^{6}$ y ejerció, en la práctica, su monopolio en el desarrollo de la moderna conserva esterilizada del pescado. A partir de los años sesenta, nuevos paises, en primer lugar EE UU y España, iniciaron su andadura en este sector. A ellos se unieron, en la década de los ochenta, Portugal y Noruega y, a comienzos del siglo xx, se incorporó Japón ${ }^{7}$.

A diferencia de los antiguos métodos de conservación del pescado, la moderna industria conservera recurre a métodos más complejos, a la vez que exige la presencia de nuevos inputs que, en muchos casos, y debido a la dificultad de conseguirlos, entorpecieron su crecimiento. Entre éstos se encuentra el aceite de oliva ${ }^{8}$.

En el proceso de elaboración de las conservas de pescado, el aceite de oliva desempeña una función imprescindible y difícil de sustituir, al menos en las primeras décadas de vida de esta nueva industria. Son dos los momentos del proceso fabril en los que el aceite interviene: por un lado, en el freído, una vez que el pescado ha sido cortado, descabezado y eviscerado. En segundo lugar, tras el enlatado del producto, en el aceitado. Estos procedimientos requieren, obligatoriamente, aceites de oliva de gran

${ }^{4}$ La invención de esta nueva técnica para conservar los alimentos se debe a Nicolás Appert, que ejerció de confitero en París en las últimas décadas del siglo xvil. A él se deben, asimismo, los primeros intentos para difundir el nuevo procedimiento. En 1810 publicó Livre de tous les ou l'Art de Conserver pendant plusiers années toutes les substances animales et vegetables, citado por F. Abreu (1983), p. 279.

5 Sobre los primeros pasos de esta invención, ver F. Abreu (1983), pp. 279-282; X. Carmona (1985), pp. 177-178.

'Sobre la industria de conservas en Francia, ver X. Carmona (1985), A. M. d'Avigneu (1958) y J. L. Decroix (1964).

7 X. Carmona (1994), pp. 128-129.

* X. Carmona (1994), p. 128. 
calidad y de sabor suave. De lo contrario, el producto final dejaría mucho que desear, tanto en la presentación, como en el sabor, el olor y, en el peor de los casos, en su deterioro total. Sólo cuando se logró perfeccionar el refino de los aceites de semillas se inició una seria amenaza para el aceite de oliva, la competencia se vio incrementada cuando, gracias a los avances en el proceso de refino y desodorización, el aceite de pescado pudo ser utilizado en estas funciones ${ }^{9}$.

En las décadas iniciales de la industria de conservas de pescado, el suministro de aceite a las fábricas que se fueron extendiendo por Europa era controlado por los franceses. El aceite de Niza era el más apreciado, el que se aseguraba para las conservas de mayor calidad y primeras marcas de las diferentes casas productoras. Su origen francés se resaltaba, situán. dolo en lugar bien visible de las latas ${ }^{10}$. En estos años el aceite español, por su mala calidad y su deficiente refino, cuando lo era, quedaba fuera de este mercado ${ }^{11}$. Ni siquiera en la naciente industria conservera española la proximidad de la producción de aceite, las abundantes cosechas o los bajos precios, propiciaron una penetración en el sector ${ }^{12}$. Hubo que esperar a que, como reacción ante la crisis agraria finisecular, se produjera una transformación radical de la industria aceitera ${ }^{13}$, lanzando al mercado aceites de calidad y a precios competitivos. En esta evolución, aunque los aceites catalanes ocuparon las primeras posiciones ${ }^{14}$, los andaluces fueron paulatinamente desplazando al resto de los españoles ${ }^{15}$.

${ }^{9}$ En el caso noruego las consecuencias de esta utilización del aceite de pescado, fundamentalmente de arenque, fueron nefastas para la exportación de aceite de oliva español. De 3.314 toneladas exportadas en 1935, se pasó a tan sólo 1.500, en 1952. Este proceso de sustitución se vio acelerado por las dificultades de la industria noruega para conseguir aceite de oliva en los años de la posguerra española y la Segunda Guerra Mundial. La Industria conservera (1947), p. 10, Fco. Zambrana, (1999), pp. 446-448.

16 F. Abreu (1998), pp. 9-14; M. Gaya (1930), p. 11.

1 Hay que advertir, sin embargo, que una parte de los aceites franceses destinados a la industria conservera procedían de comarcas españolas. De Tortosa, de sus zonas de Bitem y tierra d'Aurrubí, salían aceites de calidad hacia Marsella, donde eran enlatados bajo marca francesa y exportados. M. Gaya (1930), p. 11.

12 Sobre la industria de conservas de pescado en España, ver J. Nadal (1987), pp. 32-34; X. Carmona (1983); F. Abreu (1983); J. I. Barrón, (1992), S. Ríos (1999).

${ }^{13}$ Sobre la modernización de la industria aceitera: J. I. Jiménez (1986), Fco. Zambrana (1987), A. Parejo y Fco. Zambrana (1994), S. Hernández (1997), R. Ramón (1998).

${ }^{14}$ J. Simpson (1997), p. 286.

15 X. Carmona (1994), p. 130. Por lo que respecta al aceite de oliva español, salvo el caso de Noruega, el resto de los países productores de conservas se abastecieron, una vez consolidado el proceso de refino, de aceites andaluces, en su mayor parte. Éste sería el caso de Portugal (Cuadro 7), o de los EE UU. Sobre la evolución de la calidad de 
La industria conservera noruega es, por las circunstancias que se explican a continuación, un caso paradigmático y singular en la positiva introducción del aceite de oliva español en el mercado de la industria de conservas de pescado. En Noruega el inicio de este sector se remonta a finales de los años setenta y comienzos de los ochenta del siglo XIX, y se asentó, como en la mayor parte de las regiones donde arraigó, sobre una tradicional e importante industria de salazón, fundamentalmente de bacalao y arenque, así como en una importante flota ${ }^{16}$. Su progresión fue muy rápida, situándose en pocos años en el grupo de cabeza de países productores, junto a Portugal, España, EE UU y Japón ${ }^{17}$. En el primer tercio del siglo $\mathrm{xx}$ los principales productos elaborados por esta industria tenían como base la gran riqueza de su plataforma costera. La abundancia de pesca en la costa oeste y sur de país y la posibilidad de realizar capturas durante todo el año ${ }^{18}$, dio lugar al establecimiento de un importante número de fábricas en numerosas ciudades, entre las que destacó la de Stavanger (Cuadro 1) ${ }^{19}$. El volumen de aceite de oliva importado por estos centros conserveros fluctuaba en función de las desiguales campañas de pesca, pero, como podemos observar en el Gráfico 1, la demanda no dejó de incrementarse, de tal modo que el mercado noruego se había convertido, para la industria aceitera española, en el octavo en importancia, durante el primer tercio del siglo $\mathrm{xx}$ (Cuadro 2). Las ventas españolas a este país pasaron de 36 Tm. en 1906 a 3.035 Tm., en 1932 (Cuadro 3).

los aceites en las diferentes regiones productoras de España, ver Fco. Zambrana (1987), pp. 311-321.

${ }^{16}$ Sobre la importancia de la flota en el crecimiento económico de Noruega, ver A. Milward y S. B. Saul (1979), pp. 494-497; S. Pollard (1991), pp. 280-281; K. G. Hildebrand (1981), pp. 298-299.

${ }_{17}$ La primera fábrica fue abierta por un cocinero francés en 1841; sin embargo, su expansión no se produjo hasta la década de los años ochenta. En 1879 había 4 fábricas, a mediados de los ochenta, 29 y, en 1920, cerca de 200. Sobre la evolución de la industria de conservas de pescado en Noruega, ver E. Pereira (1943), P. Senner (1943), F. Hodne (1975).

${ }^{\text {is }} \mathrm{Al}$ contrario de otros paises, en los que la pesca se centraba en unos pocos meses, la riqueza de las costas noruegas permitía un suministro regular a lo largo de todo el año. La clave estaba en la captura sucesiva de distintas variedades de arenque. Durante el verano y el otono se pescaba el «Brisling», que, una vez ahumado, se enlataba, recubierto de aceite de oliva, y era vendido bajo el nombre de «sardinas noruegas. Brisling». En las mismas estaciones se capturaba el «Smaasild», un arenque pequeño, pariente del brisling. En primavera se pescaba el arenque de gran tamaño. La caballa, el bacalao, la langosta, y otras especies eran trabajadas también por la industria conservera noruega. Ver P. Senner (1943), p. 5.

${ }^{19}$ Entre las fuentes utilizadas para elaborar este trabajo ocupa un lugar muy destacado los fondos documentales de la Federación de Exportadores de Aceite de Oliva de España, en adelante: FEAOE. Estos fondos se ubican en la Biblioteca de la Facultad de CCEE y EE de la Universidad de Málaga. Agradezco al profesor Juan Francisco Zambrana que me haya facilitado su localización. 


\section{CUADRO 1}

Principales centros noruegos receptores de aceite de oliva (1926)

\begin{tabular}{|c|c|c|c|c|c|c|}
\hline \multirow{3}{*}{ Ciudad } & \multicolumn{6}{|c|}{ País de procedencia } \\
\hline & \multicolumn{2}{|c|}{ Francia } & \multicolumn{2}{|c|}{ Italia } & \multicolumn{2}{|c|}{ España } \\
\hline & $T m$ & $\%$ & $T m$ & $\%$ & $T m$ & $\%$ \\
\hline Fredrikshasld. & 0,36 & 0,08 & 0,00 & 0,00 & 16,08 & 0,86 \\
\hline Fredrikstald. & 0,02 & & 0,00 & 0,00 & 9,47 & 0,50 \\
\hline 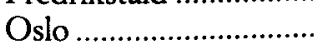 & 34,74 & 8,11 & 2,35 & 0,51 & 0,00 & 0,00 \\
\hline 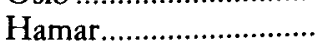 & 0,01 & 0,00 & 0,00 & 0,00 & 0,00 & 0,00 \\
\hline 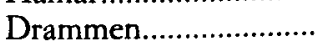 & 0,20 & 0,05 & 0,00 & 0,00 & 0,00 & 0,00 \\
\hline 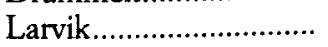 & 0,00 & 0,00 & 0,00 & 0,00 & 20,21 & 1,08 \\
\hline Skicn & 0,10 & 0,02 & 0,00 & 0,00 & 0,00 & 0,00 \\
\hline Arendal ....... & 0,01 & 0,00 & 0,00 & 0,00 & 0,00 & 0,00 \\
\hline Farsund.................... & 0,00 & 0,00 & 0,00 & 0,00 & 0,00 & 0,00 \\
\hline Stavanger ....... & 251,12 & 58,60 & 452,22 & 99,04 & $1.225,73$ & 65,27 \\
\hline Kopervik ....... & 0,00 & 0,00 & 0,00 & 0,00 & 34,74 & 1,85 \\
\hline esund .. & 0,01 & 0,00 & 0,00 & 0,00 & 62,86 & 3,35 \\
\hline 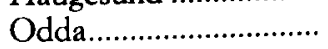 & 1,00 & 0,2 & 0,00 & 0,00 & 0,00 & 0,00 \\
\hline 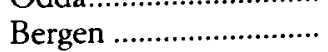 & 17,67 & 4,12 & 0,02 & 0,00 & 262,91 & 14,00 \\
\hline 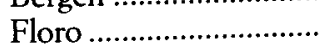 & 2,74 & 0,64 & 0,00 & 0,00 & 14,11 & 0,75 \\
\hline Aslesund ........ & 8,90 & 2,08 & 0,00 & 0,00 & 34,04 & 1,81 \\
\hline Molde .................. & 0,00 & 0,00 & 0,00 & 0,00 & 1,02 & 0,05 \\
\hline Kristisusund.. & 5,60 & 1,31 & 0,00 & 0,00 & 5,58 & 0,30 \\
\hline Trondjom & 105,94 & 24,72 & 2,02 & 0,44 & 161,02 & 8,57 \\
\hline Namsc & 0,00 & 0,00 & 0,00 & 0,00 & 0,00 & 0,00 \\
\hline Bods................ & 0,00 & 0,00 & 0,00 & 0,00 & 23,96 & 1,28 \\
\hline Harstad...... & 0,00 & 0,0 & 0,00 & 0,00 & 6,36 & 0,34 \\
\hline Vardo ........ & 0,10 & 0,02 & 0,00 & 0,00 & 0,00 & 0,00 \\
\hline 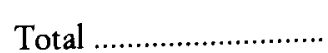 & 429,00 & 100,00 & 456,61 & 100,00 & $1.878,00$ & 100,00 \\
\hline
\end{tabular}

FuENTE: FEAOE, 1927.

En los años iniciales de la industria conservera noruega, como ocurriera en otros países, el suministro de aceite de oliva estuvo totalmente controlado por los franceses ${ }^{20}$. El hecho de haber sido Francia el país impulsor de esta industria y la innegable realidad de que disponía, en estos años finales del siglo $\mathrm{xIX}$ y primeros del $\mathrm{xx}$, de los aceites de mejor calidad, le garantizaba su hegemonía en este mercado.

${ }^{20}$ X. Carmona (1985), p. 178; M. Gaya (1930), p. 11; Bulletin des Matières Grasses (1930), p. 253. 


\section{GRÁFICO 1}

Evolución de las importaciones noruegas de aceite de oliva

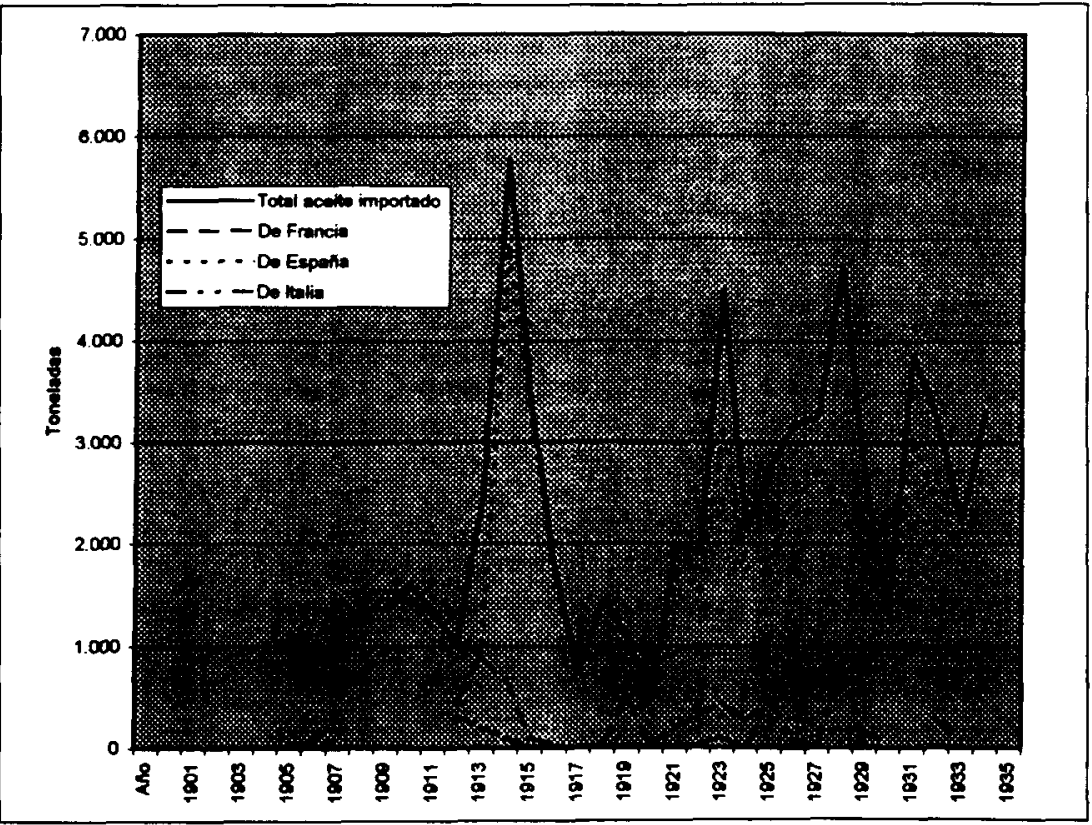

FuentE: Cuadro 3

El predominio francés, sin embargo, no se mantuvo durante mucho tiempo. En el Cuadro 3 se detecta una paulatina pérdida de importancia en favor de la implantación de los otros grandes países productores, una tendencia que se aceleró a partir de 1914, con una nítida preferencia por el aceite español.

Varios son los factores que explicarían esta consolidación del aceite español. Ante todo, estaría una circunstancia que resulta obvia, a la vista del Cuadro 3: la Gran Guerra Europea. Este conflicto involucró a Francia e Italia, y entregó el mercado conservero noruego a los exportadores españoles. Sin embargo, ésta es una circunstancia coyuntural, que afectó a otros sectores de la economía española, incluso a otros mercados de la propia industria aceitera, y sus consecuencias positivas no fueron mucho más allá 
CUADRO 2

Exportación española de aceite de oliva a los principales mercados $(\mathrm{Tm})$ (media aritmética por periodos)

\begin{tabular}{|c|c|c|c|c|c|c|}
\hline & \multicolumn{2}{|c|}{ Periodo 1901-1903 } & \multicolumn{2}{|c|}{ Periodo 1911-1913 } & \multicolumn{2}{|c|}{ Periodo 1926-1930 } \\
\hline & Exportación & $\%$ total & Exportación & $\%$ total & Exportación & $\%$ total \\
\hline Estados Unidos ... & 751 & 1,76 & 1.507 & 3,55 & 13.010 & 15,89 \\
\hline Argentina .............. & 810 & 1,90 & 7.735 & 18,24 & 13.154 & 16,06 \\
\hline Cuba ..................... & 3.989 & 9,35 & 4.264 & 10,05 & 6.579 & 8,03 \\
\hline Uruguay .............. & 273 & 0,64 & 367 & 0,86 & 6.960 & 8,50 \\
\hline Alemania ............... & 2.010 & 4,71 & 278 & 0,65 & 487 & 0,59 \\
\hline Francia ..................... & 6.263 & 14,67 & 5.169 & 12,19 & 2.959 & 3,61 \\
\hline Italia ...................... & 10.267 & 24,05 & 10.606 & 25,01 & 19.791 & 24,17 \\
\hline Gran Bretan̄a ....... & 8.778 & 20,57 & 2.771 & 6,53 & 2.901 & 3,54 \\
\hline Noruega ................ & 327 & 0,77 & 560 & 1,32 & 1.928 & 2,35 \\
\hline Otros países ............. & 9.216 & 21,59 & 9.157 & 21,59 & 14.126 & 17,25 \\
\hline Total. & 42.684 & 100,00 & 42.413 & 100,00 & 81.894 & 100,00 \\
\hline
\end{tabular}

FUENTE: FEAOE.

de unos excepcionales años de beneficios especulativos ${ }^{21}$. Por consiguiente, resulta necesario recurrir a otros factores adicionales.

Para ello hay que entender la singularidad del mercado noruego. A diferencia de otros países, en los que la demanda de aceite tenía su origen en un variado abanico de necesidades ${ }^{22}$, la demanda noruega procedía, exclusivamente, del sector de conservas de pescado ${ }^{23}$. Sus exigencias de

${ }^{21}$ Sobre las consecuencias de las Guerra Europea en las exportaciones españolas de aceite, ver Fco. Zambrana (1987), pp. 305-306; S. Hernández (1997), pp. 247-253; J. Simpson (1997), p. 287.

22 No es fácil simplificar la demanda de aceite en estos años finales del siglo XIX y primeros del xx. A una demanda industrial con destino diverso y en claro retroceso (jabones, cosmética, lubricantes, pinturas, combustible para la iluminación, etc.), hay que sumar el ascendente mercado del «aceite de boca», a su vez de gran heterogeneidad, el de la industria conservera, en sus diferentes ramas, u otros de menor entidad.

${ }^{23}$ La importación de aceite de oliva para otros usos es insignificante. Es más, aunque desde los años veinte la asociación de conserveros noruegos emprendió interesantes estudios con el objetivo de diferenciar qué tipo de aceites de oliva sería más apropiados para las distintas conservas de pescado, en la década de los años treinta aún no habian llegado a conclusiones significativas y seguian inclinándose por la importación de un aceite de oliva estándar, cuyas bondades les eran conocidas. Para las investigaciones de la industria conservara noruega sobre la idoneidad de los diferentes tipos de aceites, ver los trabajos de G. Lunde (1933), p. 112; G. Lunde y E. Mathiesen (1932), pp. 81-88; G. Lunde, E. Mathiesen y E. Mikkelsen (1933), 


\section{CUADRO 3}

Importaciones de aceite de oliva por Noruega, 1900-1935 (en toneladas)

\begin{tabular}{|c|c|c|c|c|c|c|c|c|c|}
\hline Año & Total & $\begin{array}{c}\text { De } \\
\text { Francia }\end{array}$ & $\begin{array}{l}\% \text { del } \\
\text { total }\end{array}$ & $\begin{array}{c}\text { De } \\
\text { España }\end{array}$ & $\begin{array}{l}\% \text { del } \\
\text { total }\end{array}$ & $\begin{array}{c}\text { De } \\
\text { Italia }\end{array}$ & $\begin{array}{l}\% \text { del } \\
\text { total }\end{array}$ & Otros & $\begin{array}{l}\% \text { del } \\
\text { total }\end{array}$ \\
\hline $\begin{array}{l}1900 \ldots \ldots \\
1901 \ldots \ldots \\
1902 \ldots \ldots \\
1903 \ldots . . \\
1904 \ldots \ldots \\
1905 \ldots . .\end{array}$ & & & & & & & & & \\
\hline $1906 \ldots \ldots$ & 1.117 & 1.074 & 96,15 & 36 & 3,22 & 7 & 0,63 & & 0,00 \\
\hline $1907 \ldots \ldots$ & 807 & 713 & 88,35 & 22 & 2,73 & 72 & 8,92 & & 0,00 \\
\hline $\begin{array}{l}1908 \ldots \ldots \\
1909 \ldots \ldots \\
1910 \ldots \ldots\end{array}$ & $\begin{array}{l}1.104 \\
1.355 \\
1.355\end{array}$ & 715 & 64,76 & 101 & 9,15 & 288 & 26,09 & & 0,00 \\
\hline $\begin{array}{l}1910 \ldots \ldots \\
1911 \ldots \ldots \\
1912 \ldots\end{array}$ & $\begin{array}{l}1.355 \\
1.606 \\
1.321\end{array}$ & 805 & 50,12 & 460 & 28,64 & 341 & 21,23 & & 0,00 \\
\hline $913 \ldots \ldots$ & 1.035 & 459 & 44,35 & 258 & 24,93 & 318 & 30,72 & & 0,00 \\
\hline $914 \ldots \ldots$ & 2.428 & 906 & 37,31 & 1.035 & 42,63 & 205 & 8,44 & 282 & 11,61 \\
\hline $915 \ldots \ldots$ & 5.779 & 676 & 11,70 & 4.904 & 84,86 & 100 & 1,73 & & 1,71 \\
\hline $1916 \ldots \ldots$ & 3.35 & 109 & 3,25 & 3.212 & 95,79 & 22 & 0,66 & & 0,30 \\
\hline $1917 \ldots \ldots$ & 1.759 & 32 & 1,82 & 1.669 & 94,88 & 0 & 0,00 & 58 & 3,30 \\
\hline $1918 \ldots \ldots$ & 737 & 0 & 0,00 & 737 & 100,00 & 0 & 0,00 & 0 & 0,00 \\
\hline $1919 \ldots \ldots$ & 1.456 & 38 & 2,61 & 1.018 & 69,92 & 0 & 0,00 & 400 & 27,47 \\
\hline $1920 \ldots \ldots$ & 1.101 & 459 & 41,69 & 514 & 46,68 & 22 & 2,00 & 106 & 9,63 \\
\hline $1921 \ldots \ldots$ & 484 & 37 & 7,64 & 325 & 67,15 & 27 & 5,58 & 9 & 19,63 \\
\hline $1922 \ldots \ldots$ & 2.003 & 193 & 9,64 & 1.766 & 88,17 & 29 & 1,45 & 15 & 0,75 \\
\hline $1923 \ldots$ & 1.909 & 319 & 16,71 & 1.542 & 80,78 & 29 & 1,52 & 19 & 1,00 \\
\hline $1924 \ldots \ldots$ & 4.489 & 447 & 9,96 & 3.099 & 69,04 & 103 & 2,29 & 840 & 18,71 \\
\hline $1925 \ldots \ldots$ & 2.141 & 266 & 12,42 & 1.750 & 81,74 & 0 & 0,00 & 125 & 5,84 \\
\hline $1926 \ldots \ldots$ & 2.788 & 429 & 15,39 & 1.880 & 67,43 & 457 & 16,39 & 22 & 0,79 \\
\hline $1927 \ldots \ldots$ & 3.178 & 566 & 17,81 & 2.405 & 75,68 & 73 & 2,30 & 134 & 4,22 \\
\hline $1928 \ldots \ldots$ & 3.249 & 497 & 15,30 & 2.715 & 83,56 & 17 & 0,52 & 20 & 0,62 \\
\hline $1929 \ldots \ldots$ & 4.741 & 824 & 17,38 & 2.399 & 50,60 & 849 & 17,91 & 669 & 14,11 \\
\hline $1930 \ldots \ldots$ & 2.668 & 153 & 5,73 & 2.387 & 89,47 & 7 & 0,26 & 121 & 4,54 \\
\hline $1931 \ldots \ldots$ & 1.342 & 56 & 4,17 & 1.240 & 92,40 & 14 & 1,04 & & 0,00 \\
\hline $1932 \ldots \ldots$ & 3.856 & & 0,00 & 3.035 & 78,71 & & 0,00 & & 0,00 \\
\hline $1933 \ldots \ldots$ & 3.222 & 295 & 9,16 & 2.375 & 73,71 & 250 & 7,76 & 302 & 9,37 \\
\hline $1934 \ldots \ldots$ & 2.228 & 86 & 3,86 & 2.013 & 90,35 & 5 & 0,22 & 124 & 5,57 \\
\hline $1935 \ldots \ldots$ & 3.314 & & 0,00 & & 0,00 & & 0,00 & 3.314 & 100,00 \\
\hline
\end{tabular}

FUENTE: Tidsskrit for Hermetindustri. Recogidos por la FEAOE en su informe número 1833.

pp. 375.382; E. Mathiesen (1932), en la revista Tidsskrift for Hermetikindustr, años 1932, núm. 18, pp. 71-78, y 1933, núm. 19, pp. 51-58, entre otros. 
calidad ${ }^{24}$ y la necesidad de mantener una homogeneidad y continuidad en el suministro de este input, resultaría determinante para el aceite español. La cuestión está en cómo el aceite español alcanzó a cumplir las condiciones que le imponía el mercado noruego de la industria conservera. Tres fueron las claves del éxito: la calidad, el precio y la eficiencia del empresariado español.

A) La calidad. El aceite español, especialmente el catalán, había logrado en los años finales del siglo XIX y, sobre todo, en el primer tercio del $\mathrm{xx}$, unos niveles de calidad superiores, en muchos casos, a la de los mejores aceites franceses o italianos ${ }^{25}$. A una industria conservera de pescado como la noruega, muy preocupada por la calidad de los inputs, la gran producción de la industria aceitera española le proporcionaba confianza en cuanto a la ausencia de mezclas nefastas, algo que no encontraría en industrias, como la francesa e italiana, basadas en la mezcla de aceites con muy diverso origen ${ }^{26}$.

El reconocimiento a la calidad del aceite español y su adecuación a las necesidades de la industria conservera noruega fue reiteradamente manifestado, no sólo por diversas instancias cientificas de este pais ${ }^{27}$, sino por

${ }^{24}$ Las importantes medidas para garantizar la calidad de los productos de esta industria convirtieron a Noruega en uno de los países punteros en la investigación de los inputs utilizados, así como en los procesos técnicos para la elaboración de estas conservas. En estos objetivos se produjo una coincidencia entre las autoridades noruegas y el empresariado del sector. El resultado fue la creación de un instituto específico, órgano semioficial, cuyo consejo era nombrado por el monarca, en el que destacan los estudios realizados por el «Hermetikkindustriens laboratorium». Una descripción sintética de los avances conseguidos por esta industria se puede encontrar en W. S. Hann (1948).

${ }^{25}$ Sobre la modernización del olivar y la industria aceitera española ver Fco. Zambrana (1987). En cuanto a los avances en la calidad de los aceites españoles respecto a italianos y franceses, ver R. Ramón (2000), pp. 182-188.

26 Sobre la importancia de conocer el origen de los aceites y la desconfianza de los conserveros noruegos respecto al origen de algunos aceites, ver G. Lunde (1933), pp. 112-117, y G. Lunde, E. Mathiesen y E. Mikkelsen (1933), pp. 375-382.

${ }^{27}$ En lo referente a la calidad de los aceites importados por Noruega, en su inmensa mayoria procedentes de España, las investigaciones anteriormente citadas eran concluyentes: «... No bemos podido, en ningún caso, indicar la presencia de aceites extraños en el aceite de oliva (...). Nosotros tenemos la impresión cierta de que la calidad del aceite de oliva importado en estos uiltimos años es más igual...». La preocupación de la industria conservera noruega por la calidad y por el control de las mezclas, les llevó a desarrollar una tecnología específica destinada a detectar los fraudes, adulteraciones y tipo de mezclas que caracterizaban a este producto. Esta tecnología se desarrolla en G. Lunde (1933), pp. 112-117. Dentro de este proyecto de conocer el proceso de elaboración de los aceites y las regiones donde se producían los distintos tipos, se enmarca el viaje que, en 1933, realizara a España y Francia E. Mathiesen, primer químico de la industria conservera noruega. Ver S. Hernández (1999a), pp. 305-316. 
otros países productores de aceite ${ }^{28}$. Al contrario de lo que ocurría en la industria conservera de los EE UU, España o Portugal, donde no sólo se usaba mezclas en las que el aceite refinado de oliva suponía el mayor porcentaje o la totalidad ${ }^{29}$, sino que se recurría a la mezcla con otros aceites vegetales ${ }^{30}$, en el caso noruego los aceites deberían tener un muy elevado porcentaje de aceite de oliva virgen, al que se le asignaba un mayor poder de conservación, dado su alto contenido en antioxidantes, un índice bajo de ácido libre y un sabor suave ${ }^{31}$.

De los estudios realizados en Noruega por el Hermetikkindustriens laboratorium, entre 1929 y 1933, se desprenden diferencias importantes en las características de los aceites importados de diferentes países (Cuadro 4) ${ }^{32}$. Dadas las exigencias de calidad de este mercado, los aceites

${ }^{2 k}$ En relación con la confianza que los conserveros noruegos tenían en el aceite español, la prensa especializada italiana manifestaba en 1929 , año de precios altos para este producto, lo siguiente: «... En los veinte años últimos se considera en Noruega que el aceite de oliva español es el más indicado para la conservación del "Sprat" y de los "arenques pequeños"...". L'Olivicultore, 25 de mayo de 1929, p. 2.

${ }^{29}$ E. Mathiesen (1933), p. 57.

310 US Tariff Commission (1931), p. 8. Citado por R. Ramón (2000), p. 164. En el caso de España, aunque estas mezclas estaban prohibidas para el mercado interior, en años de precios elevados para el aceite de oliva, se autorizó la mezcla de aceite de oliva con aceite de semillas para poder competir en el exterior. La Higuerita, 10 de septiembre de 1928. La autorización de estas mezclas se recoge en la RO de 25 de agosto de 1928, La Gaceta de Madrid, 26 de agosto de 1928, p. 1126.

${ }^{31}$ La legislación noruega sobre la industria de conservas de pescado exigía que el aceite de oliva no pudiera tener más de un 30 por 100 de aceite refinado. Asimismo, la cantidad de ácido libre, acidez, no debería sobrepasar el 2 por 100 . G. Lunde, E. Mathiesen y E. Mikkelsen (1933), pp. 375-382.

${ }^{32}$ En el primer tercio del siglo xx el avance en el control de la calidad del aceite de oliva, sobre todo la detección de los fraudes, se convirtió en una prioridad tanto para los países productores, como para los consumidores. En el conjunto de pruebas destinadas a estos objetivos podemos diferenciar: por un lado, las dirigidas a detectar las mezclas, bien con aceites de oliva refinados, con aceites de orujo o con otros aceites vegetales; por otro, las que estaban orientadas a comprobar la calidad de los aceites de oliva.

Entre las primeras, las más comunes eran la determinación de la densidad, la determinación del indice de refracción, y, en tercer lugar, la determinación del indice de yodo. La detección de la ausencia de mezclas exigía que se realizaran las tres pruebas. A ellas se añadieron pruebas específicas para la detección de mezclas de aceites de cacahuete, de algodón o de sésamo. A comienzos de los años treinta la industria conservera noruega incorporó el indice de fluorescencia, capaz de detectar la presencia de aceite refinado de oliva y de otros aceites en porcentajes superiores al 10 por 100.

En cuanto a la calidad, independientemente de que los aspectos anteriores estaban relacionados con ella, los indicadores más apreciados eran: el indice de acidez y el indice de enranciamiento. También era considerado por la industria noruega, aunque en un lugar muy secundario, el punto de congelación. Con relación al primero de ellos se establecían los distintos tipos y calidades de aceite virgen. Estos indicadores de calidad podían ser 


\section{CUADRO 4}

Datos analíticos del aceite de oliva en los principales paises productores. Información resumida (campaña 1932-1933)

\begin{tabular}{cccccccc}
\hline Procedencia & 1 & 2 & 3 & 4 & 5 & 6 & 7 \\
\hline Cataluña .................. & 0,91600 & 1,46700 & 110,48 & 1,13 & 6,00 & 1,12 & 83,27 \\
Andalucía ............... & 0,91610 & 1,46710 & 147,00 & 1,00 & 4,59 & 1,08 & 82,87 \\
Madrid ..................... & 0,91610 & 1,46710 & 294,00 & 1,50 & 3,30 & 0,63 & 83,00 \\
\cline { 2 - 8 } & & & \\
Total España ............ & 0,91600 & 1,46700 & 130,50 & 1,08 & 5,34 & 1,09 & 83,09 \\
Total de Francia........ & 0,91672 & 1,46707 & 149,86 & 1,57 & 7,39 & 0,77 & 84,15 \\
Total de Italia............ & 0,91650 & 1,46703 & 252,00 & 2,67 & 6,22 & 1,06 & 83,02 \\
Total de Túnez........ & 0,91720 & 1,46780 & 102,00 & 1,00 & 11,75 & 1,02 & 89,10 \\
Total de Levante ....... & 0,91625 & 1,46715 & 170,00 & 1,00 & 9,49 & 1,91 & 84,47 \\
\hline
\end{tabular}

1: índice de densidad; 2: índice de refracción; 3: indice de fluorescencia; 4: punto de congelación; 5: índice de enranciamiento; 6: ácido libre (acidez); 7: índice de yodo.

FUENTE: G. Lunde, E. Mathiesen y E. Mikkelse (1933).

franceses tenían pocas posibilidades. Su elevado índice de enranciamiento $(7,39)$, su más elevado punto de congelación y, sobre todo, su alto contenido de aceites refinados (índice de fluorescencia de 149,86), los colocaba por debajo de los aceites españoles. En similares circunstancias se encontrarían los aceites de Italia - con un muy elevado índice de fluorescencia, de enranciamiento y de congelación- o los de Túnez y Esmirna. No cabe duda que los mejor posicionados eran los aceites españoles, especialmente los catalanes. Sus características - sabor suave, reducido índice de enranciamiento y baja acidez- les permitían obtener aceites apropiados a la demanda de la industria conservera noruega sin tener que abusar de la mezcla de aceite refinado (índice de fluorescencia del 110,48) ${ }^{33}$.

Estas circunstancias, unido al volumen de la cosecha española y a los tradicionales y sólidos conocimientos del sector, hacía que los industriales

alterados mediante el refino, si bien este proceso suponía una pérdida significativa de las propiedades antioxidantes del aceite de oliva virgen, así como de otras propiedades organolépticas relacionadas con el olor y sabor, además de cotizarse a un precio considerablemente inferior. De aquí el interés por detectar estas manipulaciones.

Las referencias sobre las mezclas y los métodos de detección son profusas y aluden a múltiples aspectos del problema. Ver FEAOE (1927), G. Lunde (1933), Casamada (1935), Fco. Poggio y M. Martín (1949).

${ }^{3}$ Pese a que el aceite más apreciado para el consumo de boca y conservas era el producido en las comarcas leridanas de Borjas Blancas, Aberca, Belianes o Maldá, para las conservas de pescado el comúnmente adquirido era el tipo «Tortosa». Gaya (1930), 
y exportadores españoles, y singularmente los catalanes, pudieran asegurar un tipo de aceite estándar, con una elevada homogeneidad en las diferentes campañas. Los conserveros noruegos encontrarán en estas condiciones la confianza de no recibir mezclas no deseadas, sobre todo las elaboradas con aceite de orujo. Unas condiciones que, como podemos observar en el Cuadro 4, otros países tenían mayor dificultad en satisfacer.

B) El precio. Difícilmente podría explicarse el incremento de las exportaciones a Noruega con el simple recurso a la favorable coyuntura bélica inicial o a la calidad de los aceites españoles. Descartados los elementos culturales ${ }^{34}$ o la proximidad geográfica ${ }^{35}$, la cotización en el mercado internacional del aceite español y su relación con sus más próximos competidores constituye un factor decisivo para comprender este éxito. Aunque el precio del aceite de oliva en el mercado internacional estaba íntimamente ligado a la evolución del precio de otras grasas vegetales ${ }^{36}$, en el mercado noruego, por lo dicho anteriormente sobre la calidad, la relación habría que establecerla con las cotizaciones del aceite de oliva de otras procedencias, fundamentalmente francesa e italiana ${ }^{37}$. En la evolución seguida por los precios de este producto, a lo largo del período que nos interesa, podemos diferenciar varias etapas. En una primera, anterior al desarrollo de la industria conservera noruega, los precios más bajos en el mercado internacional correspondieron al aceite italiano. Sin embargo, a partir de 1880 y, sobre todo, a partir de 1890 , con la depreciación de la moneda española, la cotización del aceite español logró unos precios más bajos que los aceites italianos y franceses ${ }^{38}$. La ventaja definitiva vino con la consolidación y expansión, tras la crisis agraria finisecular, del olivar en España y su retroceso en Francia e Italia ${ }^{39}$.

p. 11, indica cómo «... los fabricantes de conservas noruegos adquieren esta clase, adquiriendo brillantez en el aceite, acidez de menos de un grado y esencialmente buen paladar...».

${ }^{34}$ Desde el punto de vista teórico la influencia del factor cultural e histórico, en gran medida relacionado a los movimientos migratorios, ver Gould (1994), Eichengreen e Irwin (1996). En referencia al aceite de oliva, ver R. Ramón (2000).

"25 Linneman (1996).

36. Sobre la evolución del mercado internacional de las grasas vegetales, ver Fco. Zambrana (1984), pp. 159-196.

${ }^{37}$ Sólo en 1929, año en el que el aceite español cotizó, durante unos meses, a unos precios superiores a los de sus competidores, los conserveros noruegos importaron aceite de Esmirna. Fue una importación de escaso volumen y poco satisfactoria para la industria noruega (Federación de Exportadores de Aceite de Oliva de España -FEAOE_, 1929. Informe 723). 199-240.

3* Sobre los precios en este periodo, ver GEHR (1981); Fco. Zambrana (1987), pp.

${ }^{39}$ Sobre la evolución del olivar en España: Fco. Zambrana (1987). Sobre la evolución de la producción olivarera en otros paises del Mediterráneo R. Ramón (2000), pp. 168-182. 
Como ha puesto de manifiesto Ramón (2000), durante el primer tercio del siglo xx el precio de los aceites españoles permaneció, en todo momento y en los principales mercados, por debajo de los aceites italianos o franceses. El Cuadro 5, referido a los últimos años del período considerado, refleja

\section{CUADRO 5}

Evolución de los precios

en los principales paises exportadores, 1927-1934 (en Qm)

\begin{tabular}{|c|c|c|c|c|c|c|}
\hline & \multicolumn{2}{|c|}{ España (Tortosa fino) } & \multicolumn{2}{|c|}{ Italia (Bari soprafino) } & \multicolumn{2}{|c|}{ Túnez (primera presión) } \\
\hline & Pesetas & Francos oro & Liras & Francos ono & Francos & Francos oro \\
\hline $1927 .$. & 262 & 232 & 953 & 252 & 1.128 & 229 \\
\hline $1928 .$. & 217 & 186 & 802 & 219 & 905 & 183 \\
\hline 1929 & 222 & 170 & 636 & 173 & 720 & 146 \\
\hline $1930 \ldots \ldots \ldots \ldots \ldots$ & 181 & 109 & 494 & 135 & 525 & 107 \\
\hline . & 211 & 104 & 554 & 151 & 558 & 113 \\
\hline $1932 \ldots \ldots \ldots \ldots . .$. & 206 & 86 & 471 & 125 & 402 & 82 \\
\hline $1933 \ldots \ldots \ldots \ldots \ldots$ & 171 & 74 & 397 & 107 & 311 & 52 \\
\hline $1934 \ldots \ldots \ldots \ldots \ldots$ & 171 & 74 & 484 & 129 & 334 & 68 \\
\hline
\end{tabular}

FUENTE: L'Olivicultore, núm. 3, marzo 1935, p. 37.

con más detalle esta ventaja. Sólo los precios de los aceites de Túnez, importados en grandes cantidades por Francia e Italia para elaborar sus mezclas, y los aceites de Levante podían competir con los de España. Sin embargo, como ya hemos apuntado, estos aceites no ofrecían la calidad requerida por el mercado noruego.

C) Estrategias y eficiencia de los empresarios exportadores. Es cierto que los empresarios franceses e italianos dispusieron de mejores condiciones de partida ${ }^{40}$. Su experiencia industrial y comercial, su conocimiento del mercado, así como un marco institucional muy favorable, les proporcionaron unas condiciones difíciles de superar. Esto explicaría su dominio en el último tercio del siglo xx y primeros lustros del $\mathrm{xx}$.

Sin embargo, la industria aceitera española no estaba huérfana de posibilidades. Su mayor potencial productivo y sus menores costes de pro-

\footnotetext{
40 R. Ramón (1997), pp. 49-53.
} 
ducción tal vez fueran las bazas más importantes ${ }^{41}$, pero en absoluto hemos de desdeñar el esfuerzo realizado por el empresariado del sector para superar las barreras de entrada que les imponía el mercado exterior. Como sabemos por los estudios de Zambrana (1987), Parejo (1994), Jiménez (1986), Zapata (1986), Hernández (1997) y Ramón (1997), la competitividad del aceite español ganó muchos enteros en el primer tercio del siglo $\mathrm{xx}$. No sólo se produjo la modernización del cultivo y del proceso de fabricación, que repercutieron directamente en la mejora de la calidad, sino que, parejo a estos cambios, y sobre todo a partir de la Primera Guerra Mundial, se avanzó profundamente en el campo del refino y elaboración de mezclas, a la vez que se desarrolló una activa penetración del empresariado español en el mercado exterior.

El caso del mercado noruego es más que significativo. Una vez que dispusieron de un producto de calidad, en cantidad suficiente y a precios competitivos, las estrategias seguidas por los exportadores españoles fueron muy dinámicas, despertando la atención de los medios franceses e italianos especializados, que hicieron ver al empresariado de estos países el descuido en el que, en términos comparativos, tenían a dicho mercado y, por el contrario, la gran confianza de la que gozaba el empresariado español ${ }^{42}$. En primer lugar, los empresarios españoles dedicados a la exportación se preocuparon por conseguir un aceite apropiado a las necesidades de la industria conservera noruega ${ }^{43}$. El aceite que llegaba al país nórdico era obtenido por el procedimiento de mezclas de diferentes aceites de oliva, refinado y virgen («coupages»), en las que el tipo «Tortosa» tenía un lugar

${ }^{41}$ Sobre costes de producción en España, ver Fco. Zambrana (1987), pp. 163-197; Simpson (1995), p. 168; S. Hernández (1999), pp. 193-211. Sobre los costes de producción en diferentes países de la cuenca mediterránea, ver R. Ramón (2000), pp. 176-182.

42 Una muestra de la buena reputación alcanzada por las empresas españolas la tenemos en la situación planteada por la fuerte subida de precios del aceite español en los primeros meses de 1929. La prensa especializada italiana constata cómo, ante las ofertas de empresas francesas e italianas a precios más bajos, los conserveros noruegos mantuvieron su fidelidad al aceite español: «se impone una gran tendencia y una fe absoluta en las casas (españolas) con las que se trata», L'Olivicultore, año VI, núm. 11, 25 de mayo de 1929, p. 2.

${ }^{43}$ Los propios competidores italianos reconocían esta calidad. L'Olivicultore, refiriéndose, en 1929, a los mayores precios que en esos meses tenía el aceite español indicaba: «En el último número de la revista de los fabricantes noruegos de conservas alimenticias, éstos bacen interesantes apreciaciones dignas de conocerse, declarándose, desde luego, decididos protectores del mercado español. Se afirma rotundamente en dicho órgano de publicidad, que el aceite de oliva español es de superior calidad al de otras procedencias, y que en cuanto a la aplicación a la industria conservera reúne cualidades intrínsecas inmejorables, baciendo sobresalir la excelencia del aceite español..., Recogido por la Hoja Informativa, FEAOE, Informe 723, año 1929. 
preferente ${ }^{44}$. Cada año estas mezclas alcanzaba una mayor homogenei$\mathrm{dad}^{45}$, consiguiendo un aceite caracterizado por su gran brillantez, una acidez en torno a un grado y un buen paladar. Sólo a partir de 1930, en gran medida como consecuencia del incremento de precios, de la restricción de la oferta que se produjo en el aceite español en los primeros meses de 1929, y del riesgo de que pudieran comprar aceites adulterados, los conserveros noruegos tomaron la iniciativa y emprendieron una serie de proyectos encaminados a conocer la situación de la oferta de aceite de oliva en los principales países productores ${ }^{46}$, así como las posibilidades de otras grasas. En segundo lugar, los exportadores españoles pusieron mucho cuidado en que este producto no sufriera alteraciones por su almacenaje o transporte. El aceite que se enviaba a Noruega era el único envasado en barriles de madera de castaño que, a diferencia de los de roble, evitaba la alteración en el sabor del aceite. En los años treinta estos envases estaban siendo sustituidos por otros de acero, interiormente estañados ${ }^{47}$. En tercer lugar, los exportadores desarrollaron técnicas comerciales que indujeron a los conserveros noruegos a permanecer ligados a la oferta espanola. Para ello consiguieron una sólida red de agentes de venta en Noruega, con su centro en Stavanger, que visitaban regularmente a sus compradores, con objeto de tener un conocimiento puntual de sus preferencias. Además fijaron formas de pago, entre treinta y noventa días, más ventajosas que la de sus competidores ${ }^{48}$.

\$4 M. Gaya (1930), p. 11.

45 En los repetidos análisis que los laboratorios de la industria conservera noruega realizó de los aceites importados, así como en las constataciones que el químico Mathiessen lleva a cabo en nuestro país, se pone de manifiesto este procedimiento y sus buenos resultados.

${ }^{46}$ Estos proyectos estuvieron guiados básicamente a conseguir una mayor independencia de la industria conservera noruega en este inpust. Para ello se emprendió una doble línea: por un lado, asegurarse la calidad de los aceites que adquirían y la ausencia total de adulteraciones no deseadas y fraudes. Por otro, buscar aceites, de oliva o de otra procedencia, que paliarán la gran dependencia del aceite español. En la primera dirección el «Hermetikkindustriens laboratorium» inició, en 1929, diferentes proyectos de investigación que acabaron con la obtención de un método propio para detectar las mezclas: el índice de fluorescencia. En la segunda línea, las investigaciones fueron más lentas. Sólo en los años cuarenta se conseguiría un método para obtener aceite de pescado que respondiera a las exigencias de los empresarios noruegos.

47 En la visita del noruego Mathiesen a los centros exportadores españoles se hace eco de este cuidado: «En todos los depósitos que yo visité, sin excepción alguna, era rarísimo ver una fábrica de madera y los fabricantes de aceite sostenían que ellos exportaban el aceite en bidones de hierro o "drums", prácticamente hablando a todos los otros mercados excepto a los de Noruega», E. Mathiesen (1933), p. 57.

4os medios especializados italianos reconocían el gran trabajo llevado a cabo en Noruega por los exportadores españoles y la necesidad de imitarlos si quería avanzar en 


\section{EMPRESAS Y EMPRESARIOS ESPAÑOLES EN EL MERCADO NORUEGO}

Esta progresión tan positiva de los aceites españoles en el mercado noruego nos lleva a preguntarnos sobre las empresas que lo protagonizaron. El análisis se puede hacer desde perspectivas diversas. En primer lugar, interesa la búsqueda de elementos que permitan establecer las similitudes y las diferencias entre ellas. Por otra parte, conviene conocer los niveles de especialización de las diferentes regiones españolas productoras de aceite. Un tercer enfoque buscaría contrastar la presencia e importancia relativa.

Las fuentes para este análisis son las declaraciones juradas presentadas por las empresas exportadoras españolas para el periodo de tiempo de enero de 1930 a julio de $1935^{49}$, el Registro Oficial de Exportadores, creado por RO de 11 de diciembre de $1929^{50}$, los Libros de Registro de Sociedades del Registro Mercantil de las diferentes provincias andaluzas y los Anuarios Financieros. Desgraciadamente, estas fuentes no permiten establecer un seguimiento de la implantación de las diferentes empresas a lo largo del período estudiado, pues los datos de los que disponemos sólo hacen referencia al quinquenio de 1930-1935, globalmente considerado. Habrá que esperar a que se lleven a cabo estudios monográficos sobre estas sociedades para comprender cómo fueron sus trayectorias en éste y otros mercados. Mientras tanto, algunas conclusiones sí que podremos obtener, por pobres que éstas sean, de los datos disponibles.

En primer lugar, se constata que, pese a las singularidades del mercado noruego, no son pocas las empresas exportadoras que estaban presentes (Cuadro 6). Veintiuna empresas, de las 49 que presentaron sus declara-

este mercado: «El lugar que ocupa actualmente España en Noruega se debe, especialmente, a la actividad de los exportadores que no dejan ningún año de visitar a la clientela para conocer mejor sus gustos y preferencias. Es indiscutible que la penetración en un mercado sólo puede conseguirse con sacrificio (...). Nuestros exportadores deberán adoptar el mismo sistema de pago que conceden los españoles, que es generalmente de tres meses y más», FEAOE, 1927.

49 Estas declaraciones, en las que figuran las exportaciones a la totalidad de los mercados aceiteros llevadas a cabo por las empresas exportadoras españolas, fueron recogidas por la FEAOE, en octubre de 1935. Sin embargo, no todas las empresas exportadoras españolas habrían entregado estas declaraciones. El Registro de Exportadores llega a contabilizar hasta 80 empresas (Gaceta de Madrid, 11 de enero de 1933). Ignoramos la importancia de las ausentes en el volumen total del aceite exportado y sus mercados preferentes. No obstante, entendemos que las que entregaron la documentación exigida a la FEAOE serían las más importantes del sector.

51" Gaceta de Madrid del 29 de diciembre de 1929. En 1932, el gobierno de la República, por Orden del 8 de octubre de 1932, del ministerio de Agricultura, Industria y Comercio, confirmó este Registro de Exportadores. 


\section{CUADRO 6}

La exportación de aceite de oliva español a Noruega (en Tm) Exportadores y origen de la exportación. Periodo: enero de 1930-julio de 1935

\begin{tabular}{|c|c|c|c|c|c|}
\hline Empresa & $\begin{array}{c}\text { Año } \\
\text { constitu. }\end{array}$ & $\begin{array}{c}\text { Exp. } \\
\text { Noruega }\end{array}$ & $\%$ & $\begin{array}{l}\text { Exp. } \\
\text { total }\end{array}$ & $\begin{array}{c}\text { Exp. } \\
\text { Norregal } \\
\text { total }\end{array}$ \\
\hline Carbonell (Córdoba), S. C........... Córdoba & 1866 & $1.243,96$ & 9,61 & $31.726,33$ & 3,92 \\
\hline Dulken (E. Van), R. C. .................. Málaga & 1932 & 392,40 & 3,03 & $12.069,94$ & 3,25 \\
\hline Luca de Tena (Hijos de), R. C. ... Sevilla & 1891 & 4,85 & 0,04 & $6.205,66$ & 0,08 \\
\hline Maestroni, S. A ......................... Málaga & 1926 & $1.328,90$ & 10,27 & $6.783,82$ & 19,59 \\
\hline Minerva, S. A. .............................. Málaga & 1919 & 337,26 & 2,61 & $29.523,26$ & 1,14 \\
\hline Pallarés Hermanos, R. C.............. Córdoba (Cabra) & 1917 & 708,28 & 5,47 & $8.085,61$ & 8,76 \\
\hline Riva Hermanos, S. A ..................... Málaga y Jaén & 1926 & 75,97 & 0,59 & $6.410,56$ & 1,19 \\
\hline Utrerana, S. A., La ........................ Sevilla (Utrera) & 1923 & 15,10 & 0,12 & 205,04 & 7,37 \\
\hline barra (Hijos de), S. C.................. & 1885 & 61,30 & 0,47 & $27.776,04$ & 0,22 \\
\hline Moro, S. A & 1926 & 321,80 & 2,49 & $19.589,90$ & 1,64 \\
\hline \multicolumn{2}{|c|}{ 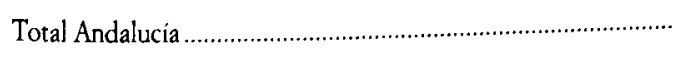 } & $4.489,82$ & 34,69 & $148.376,16$ & 3,03 \\
\hline \multirow{9}{*}{$\begin{array}{l}\text { Ballester Romero, Juan ................ Tarragona (Tortosa) } \\
\text { Basseda, Antonia ........................ Barcelona } \\
\text { Fontana, Enrique ...................... Tarragona } \\
\text { Gasull (Est. Félix) ....................... Tarragona (Reus) } \\
\text { Hijos de José Sabater ................. Tarragona (Reus) } \\
\text { Mangrané, Daniel...................... Barcelona } \\
\text { Pallarés, Fernando ..................... Barcelona } \\
\text { Pedrol, Manuel. }\end{array}$} & & $2.798,64$ & 21,62 & $8.948,01$ & 31,28 \\
\hline & 1850 & 758,11 & 5,86 & $1.047,86$ & 72,35 \\
\hline & & 112,52 & 0,87 & $6.647,87$ & 1,69 \\
\hline & 1922 & 898,16 & 6,94 & $11.100,72$ & 8,09 \\
\hline & & $1.109,91$ & 8,58 & $8.587,70$ & 12,92 \\
\hline & & $1.305,24$ & 10,09 & $1.463,66$ & 89,18 \\
\hline & 1932 & $1.084,94$ & 8,38 & $3.057,68$ & 35,48 \\
\hline & & 326,47 & 2,52 & $5.647,09$ & 5,78 \\
\hline & & $8.393,98$ & 64,86 & $46.500,59$ & 18,05 \\
\hline Cía. Exportadora Española .......... Madrid & 1933 & 34,57 & 0,27 & $5.822,67$ & 0,59 \\
\hline Salgado y Cía.............................. Madrid & 1920 & & 0,17 & $2.858,00$ & 0,76 \\
\hline Tolad Mid & & 56,32 & 0,44 & $8.680,67$ & 0,65 \\
\hline Ballester y Cia. ............................. Valencia & & 2,23 & 0,02 & $1.764,06$ & 0,13 \\
\hline Total Valencia . & & 2,23 & 0,02 & $1.764,06$ & 0,13 \\
\hline & & $12.942,34$ & 100,00 & $205.321,48$ & 6,30 \\
\hline
\end{tabular}

FUENTE: Resumen de las declaraciones de exportación presentadas a la FEOE, Informe 2.539; Registros Mercantiles provincias andaluzas; Anuarios financieros.

ciones al Registro Oficial de Exportadores, mantuvieron relaciones comerciales con la industria conservera de este país. Esto indicaría que, dadas las exigencias de calidad y el tipo de aceite demandado por la industria 
conservera noruega, existía un empresariado activo, conocedor del mercado exterior y dispuesto a penetrar en él.

En segundo lugar, una agrupación de estas empresas por el lugar donde estaban radicadas, pone de manifiesto el claro predominio del sector exportador catalán sobre el otro gran foco exportador, Andalucía ${ }^{51}$. Nada de extraño tiene este predominio de las empresas catalanas, ya que, como hemos indicado, esta industria fue la primera en conseguir aceites de calidad $^{52}$. Asimismo, los aceites elaborados en Cataluña, independientemente de que fueran producidos en ésta u otra región ${ }^{53}$, eran adaptados, mediante mezclas, a las exigencias de los conserveros noruegos ${ }^{54}$. Sus aceites vírgenes tenían un sabor más suave, menos intenso que los andaluces, por lo que no requerían ser rebajados con aceite refinado. Del mismo modo, su experiencia comercial y su implantación en los mercados exteriores había sido anterior al resto de las regiones productoras españolas 55 .

De las 21 empresas que exportaban a Noruega, 10 se localizaban en Andalucia. Por su objeto social, por el volumen de capital que movilizan y por las características de sus socios, poco tienen que ver estas empresas con las que se habían constituido para el cultivo del olivar o de la fabricación del aceite ${ }^{56}$. El elevado volumen de exportaciones alcanzado por algunas de ellas, de fecha de constitución muy próxima al período al que se refieren los datos (Dulken, R. C.; Maestroni, S. A.; Pallarés Hermanos, S. A.; Miner-

${ }^{51}$ Creemos necesario aclarar que cuando nos referimos a empresas exportadoras catalanas o andaluzas, estamos aludiendo al lugar donde están radicadas, Cataluña o Andalucía, y no al origen de su empresariado o capital. Un número importante de empresas localizadas en las provincias andaluzas fue constituido por empresariado y capital de otras regiones, fundamentalmente catalanes, aunque también están presentes madrileños o vascos.

52 J. Simpson (1997), p. 286.

53 Por Cataluña no sólo se exportaban los caldos producidos en las comarcas aceiteras de esta región, sino que las empresas exportadoras de Tarragona, Reus o Barcelona daban salida, además, a los aceites del Alto y Bajo Aragón y del Valle del Ebro, incluso de Andalucía. El aceite de mayor implantación en la industria conservera noruega, «la clase Tortosa», no era otra cosa que el resultado de una serie de mezclas de distintas procedencias, que poco tenía que ver, ni por la cantidad producida, ni por sus características, con el que se obtenía en los años treinta en las comarcas de Tortosa. Ver E. Mathiesen (1933), p. 53.

${ }^{54}$ Como se ha indicado en otro lugar, la industria conservera noruega exigía que el aceite utilizado fuera, al menos, en un 70 por 100 , virgen. Los aceites andaluces vírgenes tenían un fuerte sabor al fruto, por lo que, dado los gustos de la demanda, se solían mezclar en una proporción del 30 por 100 virgen y 70 por 100 refinado. Esta singularidad dificultaba la expansión de los aceites andaluces en el mercado noruego.

ss Sobre la temprana presencia de los exportadores catalanes en los distintos mercados, ver R. Ramón (1997), pp. 49-50.

5t Una caracterización del empresariado agrícola y fabricantes de aceite de oliva, en este caso referida sólo a la provincia de Jaén, podemos encontrarla en S. Hernández (1997), pp. 338-356. 
va, S. A.; Moro, S. A.; Riva Hermanos, S. A.; La Utrerana, S. A.), sugiere que una parte significativa de sus promotores habría de tener una importante experiencia en el sector. Es decir, se trataría de nuevas empresas, con nueva ubicación, constituidas por «viejos empresarios», procedentes, en muchos casos, de otras regiones con más experiencia en el sector.

Las diferencias entre las empresas catalanas y andaluzas se hacen más evidentes si, en vez de referirnos al volumen exportado a Noruega, prestamos atención al peso de esas exportaciones en relación con sus exportaciones totales (Cuadro 6). En este caso, se constata un nivel de concentración mucho mayor en las catalanas que en las andaluzas. Para estas últimas el mercado noruego supondría solamente el 3,03 por 100, para las catalanas, el porcentaje se eleva al 18,05 por 100 . Por empresas, en Andalucía sólo hay tres en las que el mercado noruego tenía un peso significativo, Maestroni, S. A. (19,59 por 100), Pallarés Hermanos, S. A. $(8,76$ por 100) y La Utrerana, S. A. (7,37 por 100). Las tres son empresas de reciente creación, en las que el empresariado de origen catalán y relacionado con el mercado noruego tenía una importante presencia ${ }^{57}$. Por el contrario, para un número importante de empresas catalanas el mercado noruego era un interesante destino.

\section{LA EXPORTACIÓN ESPAÑOLA A LOS MERCADOS MÁS IMPORTANTES}

A la luz de estos datos consideramos de interés preguntarnos sobre esta relación empresas catalanas-empresas andaluzas en el conjunto de la exportación española, y establecer una comparación entre la imagen que refleja el mercado noruego y el conjunto de la exportación española de aceite de oliva. Entendemos que el grado de presencia de dichas empresas

57 De estas tres empresas, la primera en establecerse fue Pallarés Hermanos, Sociedad Regular Corigen catalán, de Tortosa, se estableció en Cabra en 1917 con un 500.000 ptas. En 1928 se transformaria en sociedad anónima ampliando su capital hasta 7.000 .000 de ptas. La segunda de estas empresas, La Utrerana, S. A., fue creada en 1923. Entre sus socios figuraba el barcelonés Daniel Mangrané Bocardo, de la empresa Daniel Mangrané, de Barcelona, que aportó la mayor parte del capital social de la empresa en el momento de su constitución (1.250.000 ptas., de un total de 1.300.000). En posteriores ampliaciones entrarian a formar parte de la sociedad nuevos empresarios catalanes. Éste es el caso de los miembros de la conocida familia de exportadores de aceite Francisco y Pedro Bau Blasi, o de Francisco Bau Nolla. La empresa Maestroni, S. $A$, se creó en 1926. Entre sus socios figuran de nuevo los hermanos Pallarés. 
en los diferentes mercados ayudará a explicar la evolución del sector, y a entender de forma más ajustada el caso noruego.

Los más de 70 mercados con los que estas empresas mantenían relaciones comerciales los hemos reducido a los más importantes, 9 en total. A su vez, éstos los hemos agrupado en tres bloques: EE UU, América Latina (Argentina, Cuba y Uruguay) y Europa (Francia, Inglaterra, Italia, Portugal y Noruega). El escenario dibujado ahora por el Cuadro 7 es considerablemente distinto. En este caso, el mayor volumen de exportaciones fue canalizado a través de empresas radicadas en Andalucía, invirtiéndose casi la proporción: un 70,58 por 100 de Andalucía, frente a un 25,19 por 100 de Cataluña ${ }^{58}$, cuotas de mercado muy similares a la capacidad de producción de aceite en las dos regiones, ya que entre 1930 y 1935 el aceite andaluz suponía el 62 por 100 del total español ${ }^{59}$.

El Cuadro 7 nos permite hacer algunas consideraciones adicionales sobre las empresas exportadoras en ambas regiones. En primer lugar, es interesante llamar la atención sobre cómo, en las dos regiones, la concentración de las ventas ${ }^{60}$ en los tres destinos principales es superior al 70 por 100 para todas las empresas. Además, las de menor tamaño observan los mayores niveles de concentración en determinados mercados ${ }^{61}$. En segundo lugar, las empresas catalanas, en su conjunto, tenían una presencia similar en los mercados de Europa (42,14 por 100) y América del Sur (48,06 por 100), quedando el mercado estadounidense muy lejos de éstos $(9,78$ por 100$)$. Una imagen distinta presentaban las empresas andaluzas,

sk Las exportaciones declaradas por estas empresas, para el período de 1930 -julio de 1935, equivalen al 69,75 por 100 del total de las exportaciones españolas de aceite de oliva registrada por la Dirección General de Aduanas durante ese mismo período. Segín estas dos fuentes, los países donde estas empresas canalizarian un menor volumen de la exportación española serian: Italia, donde controlarian el 77,93 por 100 y, sobre todo, Francia, con el 35,22 por 100. Los datos de la exportación española por las diferentes aduanas los hemos obtenido de Fco. Zambrana (1987), pp. 431-436.

59 Fco. Zambrana (1999), p. 442.

(6) Se define el «índice de concentración por destinos» de las exportaciones de aceite de la empresa $\mathrm{j}$ como el cociente entre la suma de las exportaciones a los tres destinos más importantes, en términos absolutos, y el total exportado:

$$
I C=\frac{E_{1 j}+E_{2 i}+E_{3 i}}{E}
$$

Siendo:

$E_{1 j}, E_{2 j}$ y $E_{3 j}=$ Exportaciones de la empresa $j$ hacia los tres paises con mayor aportación a la exportación total de dicha empresa.

$E=$ Exportaciones totales de la empresa $j$.

${ }^{6}$ En este caso el indicador de tamaño de la empresa sería el volumen de sus exportaciones. 


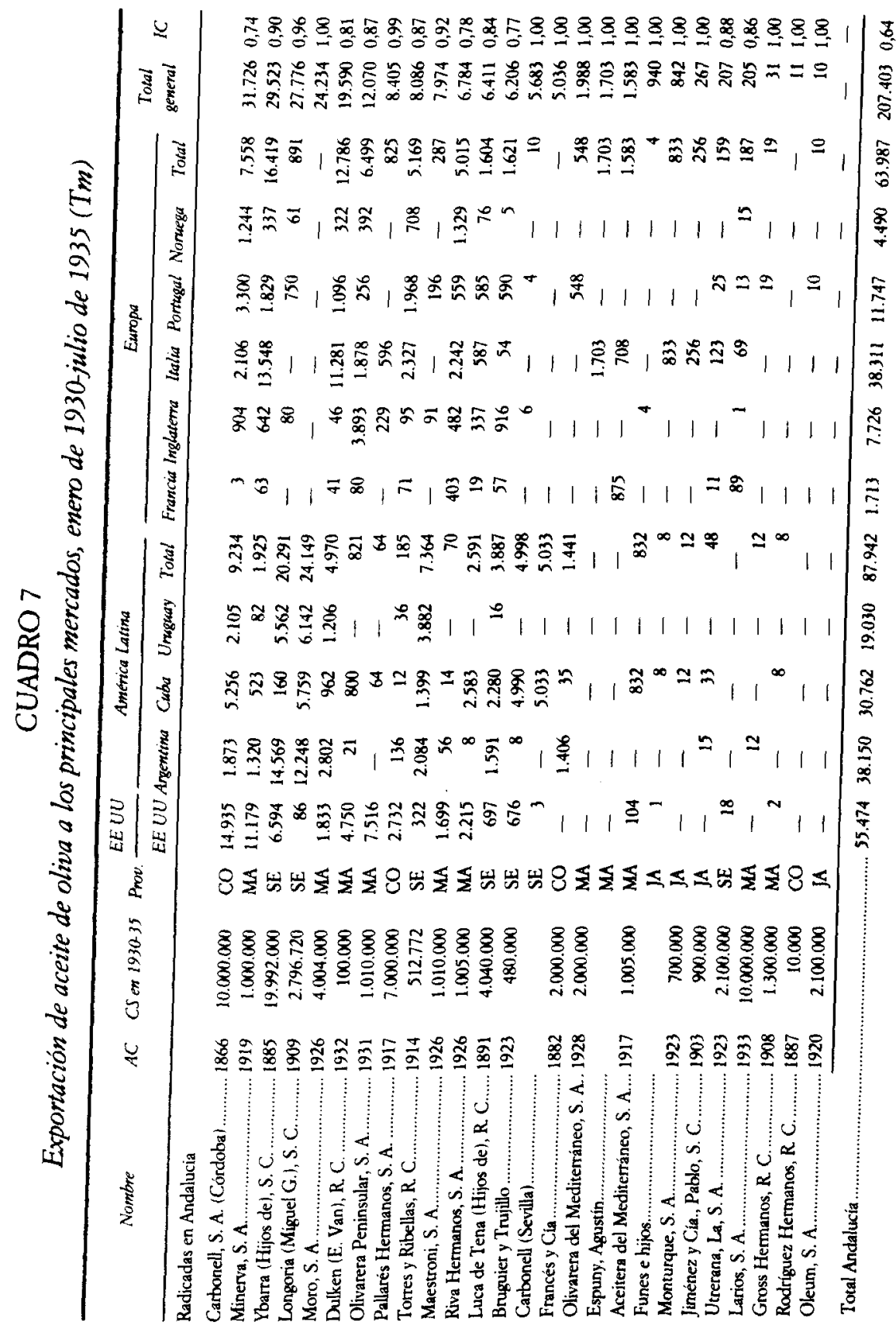




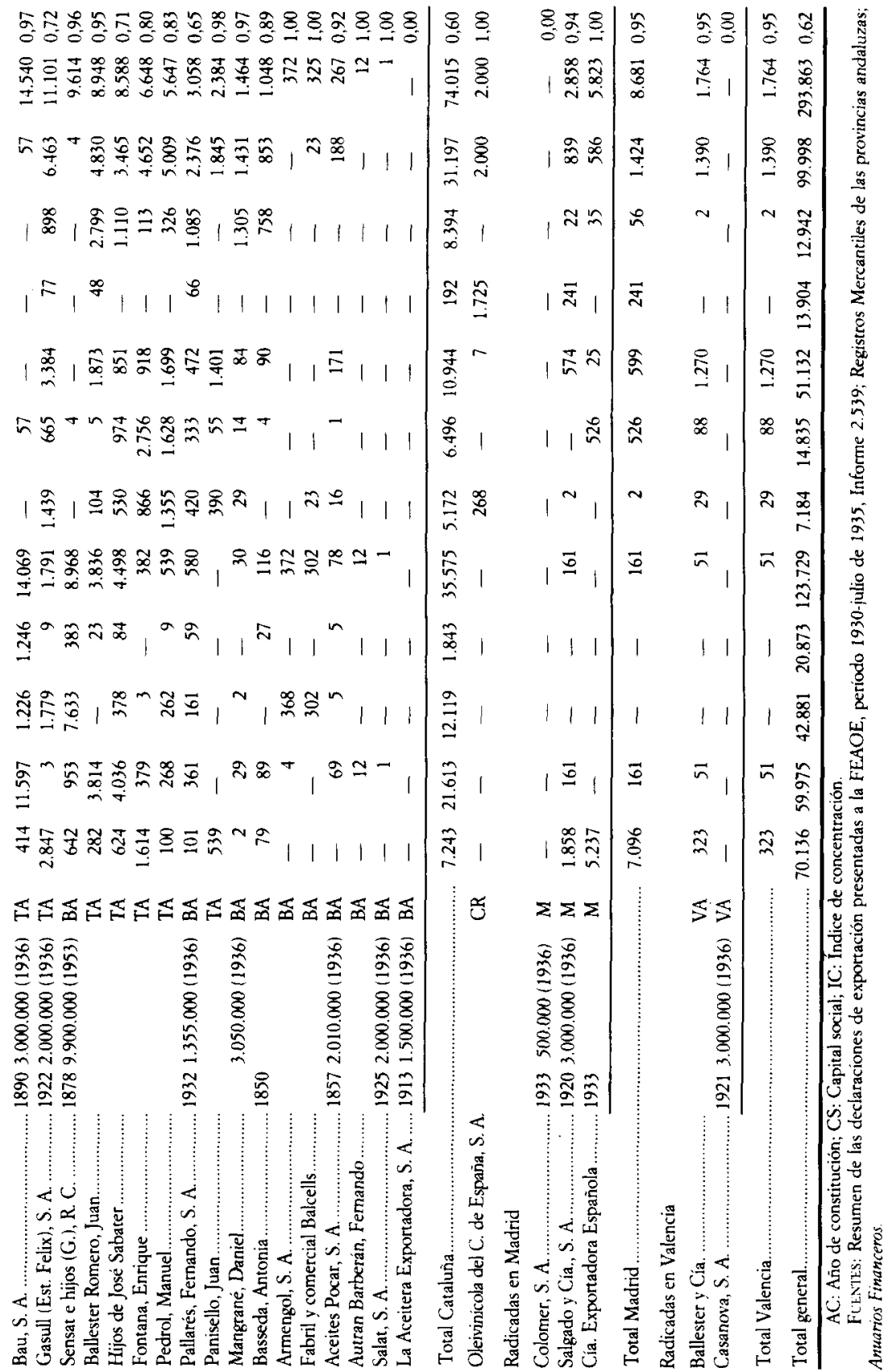


pues, aunque el orden es el mismo, el peso de los EE UU es muy superior al que representaba este mercado para las catalanas $(26,74$ por 100$)$, y en cambio, el mercado europeo es, en términos relativos, considerablemente inferior $(30,85$ por 100$)$.

En un análisis más detallado, prestando atención a cada una de las empresas de las dos regiones, se confirma la importancia del mercado europeo para las empresas catalanas. Ciertamente, algunas grandes empresas de esta región concentraban el grueso de su negocio en América Latina, mercado en el que tendrían un gran arraigo y prestigio ${ }^{62}$, caso de Bau, S. A. $(96,76$ por 100$)$, o Sensat e bijos $(93,28$ por 100$)$, sociedades de temprana creación, pero la mayoría de ellas dirigen el mayor porcentaje de sus exportaciones al mercado europeo. En el caso andaluz, aunque también había un nutrido grupo, de entre las grandes empresas, que tenía en Europa un importante destino de sus ventas, son los EE UU y Latinoamérica sus grandes mercados.

Conocer las causas de esta distribución de las exportaciones de las dos grandes regiones productoras requeriría estudios específicos sobre cada uno de estos mercados y su evolución en el tiempo. Algo se ha avanzado en este camino. Los recientes trabajos de Ramón son sin duda una valiosa aportación ${ }^{63}$, pero aún queda mucho por hacer, fundamentalmente en el estudio de las estrategias empresariales. La información disponible en estos momentos no permite afirmaciones concluyentes en este terreno, sobre todo teniendo en cuenta la complejidad de los distintos mercados; sin embargo, sí permite avanzar que la mayor o menor importancia de Europa, EE UU o América Latina en las dos grandes regiones exportadoras españolas no responde, en los años a los que se refieren estos datos, a una especialización en diferentes nichos de mercado, en la exportación de aceites de mayor o menor calidad.

Del Cuadro 7 y de los fondos documentales de la AEAOE, se desprende que, salvo segmentos de mercado muy específicos y minoritarios, que estaban dominados por aceites catalanes de gran calidad, ya sean para el consumo de boca ${ }^{64}$, para encabezar algunas mezclas ${ }^{65}$, o de aceites de características muy concretas, caso de la industria conservera noruega, en el

${ }_{62}$ Algunas notas sobre la presencia de estos empresarios en América podemos encontrarlas en R. Ramón (1997), p. 50.

${ }^{63}$ Una aproximación a las características de los diferentes mercados podemos encontrarla en R. Ramón (2000), pp. 159-197.

${ }_{64}$ En un informe emitido, en 1930, por la Oficina Comercial de España en Londres se indica que en Inglaterra el aceite de oliva español para usos alimenticios procede de Tortosa y del Bajo Aragón: «Las clases selectas del país, que son, sin disputa, las mejores con- 
resto del mercado estaban presentes los aceites de ambas regiones, sin que se pueda establecer una especialización por destinos en función de la región de procedencia. Son las empresas y no el origen geográfico del aceite, las que marcan la mayor o menor implantación en uno u otro mercado, en uno u otro uso. En esta línea apuntaría el hecho de que el índice de concentración de las ventas, en todos los casos, sea superior en el ámbito de las empresas, que en el ámbito de las dos regiones.

La exportación que generaba un mayor valor añadido, la realizada en pequeños envases y bajo marca, es un claro ejemplo. Centrándonos en uno de los mercados menos complejos, el de Uruguay, quinto en importancia para la exportación española, donde la práctica totalidad del aceite importado se hacia bajo marca ${ }^{66}$, y la presencia italiana era muy reducida ${ }^{67}$, se observa cómo fueron las empresas radicadas en Andalucía las que acapararon el 91,17 por 100 del mercado. Las mismas empresas andaluzas estaban presentes, con gran peso, en Cuba, Argentina y los EE UU. Junto a ellas figuraban empresas catalanas de conocido arraigo en el mercado americano.

Esta evidencia sugiere que fueron las empresas españolas con mayor experiencia y mejor capitalizadas, independientemente de la región donde estuvieran radicadas, las que controlaron el segmento de mercado más lucrativo, la comercialización bajo marca ${ }^{68}$ : Carbonell, S. C.; Hijos de Ybarra, S. C.; Miguel G. Longoria, S. C.; Hijos de Luca de Tena, R. C., entre las andaluzas; Bau, S. A.; Sensat e Hijos, Ballester Romero, entre las catalanas.

En segmentos del mercado menos exigentes, fundamentalmente la exportación en grandes envases, bien para uso industrial ${ }^{69}$, bien para la

sumidoras de aceite de oliva, lo que desean es el aceite puro, virgen, de primera presión, y de regiones donde, naturalmente, sea más ligero y más refinado. Al decir refinado nos referimos a un refinamiento natural, no al manipulado...». Recogido por la AEAOE (1930), Informe núm. 1.399 .

65 Sobre la preferencia de los industriales franceses por los aceites catalanes de calidad, ver AEAOE (1930), Suplemento al informe núm. 1.396: «La olivicultura en Lérida»; $M$. Gaya (1930), p. 11; E. Mathiesen (1933), p. 54.

th En el quinquenio de 1928-1932, la importación en envases pequeños supuso el 87,23 por 100 del total. FEAOE (1932), Memoria, pp. 264-265.

${ }^{67}$ L'Olivicultore, abril de 1934, núm. 4, p. 45.

6. Ramón ha puesto de manifiesto cómo la comercialización de aceite marca requiere una importante dotación tanto de capital físico y humano. R. Ramón (1997), pp. 49-50.

69 A comienzos de los años treinta, España era la principal suministradora de aceite de oliva para uso industrial a Inglaterra. Este aceite se empleaba casi exclusivamente en la industria textil, con el fin de restituir a la lana parte de la materia grasa que pierde 
industria de conservas de pescado -excluida Noruega $-{ }^{70}$, o bien para ser mezclado y vuelto a envasar por los llamados países intermediarios -Francia, Portugal e Italia- o las industrias aceiteras nacionales de EE UU y Argentina ${ }^{71}$, estuvieron también presentes las empresas de ambas regiones, si bien en el mercado de los EE UU, caracterizado por la importación de aceite español en grandes envases, ocuparon un lugar destacado las empresas andaluzas, con el 79,09 por 100 de la exportación. El noruego Mathiesen, tras su visita a la industria aceitera española, indicaba que era de Málaga de donde salía la mayor parte de estos aceites exportados en grandes envases. El importante número de empresas de reciente constitución en esta ciudad, durante o tras la Gran Guerra Europea, y la importancia que para estas empresas tenían los países intermediarios y los EE UU apuntaría en esta dirección. Asimismo, en 1932, por el puerto de Málaga se exportaba el 36,92 por 100 de los aceites en grandes envases, frente a tan sólo el 8,57 por 100 en envases pequeños ${ }^{72}$. Sin embargo, la confirmación, cuantificación y significado de estos extremos es algo que está por investigar.

\section{CONCLUSIONES}

$\mathrm{El}$ análisis del caso noruego pone de manifiesto que el sector aceitero español había experimentado, en el primer tercio del siglo $\mathrm{XX}$, una profunda transformación que le habría permitido penetrar en un mercado altamente exigente en calidad, desalojando del mismo a sus principales competidores, Francia e Italia.

A partir de él puede deducirse que el éxito alcanzado por el aceite español, en un mercado caracterizado por un alto nivel de exigencia y por la ausencia de elementos culturales e históricos que pudieran condicionar la demanda, estuvo basado en tres factores fundamentales: $a$ ) en

en el lavado. El aceite utilizado en esta labor era aceite de oliva, no de orujo, de mayor acidez que el destinado para consumo humano. Procedía «de Andalucía y se embarca en Málaga y Sevilla .... FEAOE (1930), Informe 1.399.

${ }^{70}$ Éste sería el caso de Portugal o EE UU.

Sobre la mezcla de aceites de semillas con aceite de oliva por parte de la industria aceitera argentina, ver FEAOE (1927), Informe núm. 45. Según la Memoria de la FEAOE de 1932, en el quinquenio de 1928-1932 el aceite en grandes envases supuso el 31,70 por 100 del total del aceite español exportado a Argentina. Sobre este tipo de exportación a los EE UU, ver FEAOE (1927), Informe núm. 139: «El aceite de oliva en los EE UU de Norteamérica».

72 FEAOE, Memoria de 1932, p. 271. 
la disponibilidad de una importante cosecha de aceite de calidad, que permitía abastecer la demanda con la garantía de no tener que recurrir a aceites de otras procedencias; $b$ ) la permanencia durante todo este período de precios competitivos, inferiores, en todo momento, al precio de los aceites italianos y franceses, y c) la gran capacitación del empresariado exportador español, tanto en la elaboración de mezclas, como en el recurso a técnicas de mercado que les aseguraron la confianza de los industriales noruegos.

$\mathrm{El}$ análisis de las empresas que intervinieron en la exportación a Noruega evidencia el control de este mercado por las empresas radicadas en Cataluña. En ello influiría tanto la mayor experiencia del empresariado catalán como la mejor adaptación de los aceites elaborados en esta región a la rígida demanda de la industria conservera noruega, que exigía aceites de baja acidez, suave sabor y alto porcentaje de aceite virgen. La comparación de la exportación al país nórdico con la exportación al resto de los mercados nos ofrece escenarios muy diferentes. En la mayoría de estos mercados la demanda no fue tan rígida como en caso noruego. En estas circunstancias, el aumento de la cosecha andaluza, la aparición de nuevos métodos de refino y la difusión de los conocimientos sobre selección y mezclas de aceites, unido a la ventaja de menores costes y mayor productividad de las comarcas olivareras andaluzas, hicieron que las empresas radicadas en Andalucía adquirieran, en la exportación española, un significado próximo a la capacidad productora de la región. En este avance de la región andaluza la menor dotación de factor empresarial quedaría resuelta, en cierta medida, con el establecimiento en Andalucía de un importante número de empresarios procedentes de otras regiones, fundamentalmente catalanes.

\section{BIBLIOGRAFÍA}

Abreu Fernández, Fernanda (1983): La formación de capital en la ría de Vigo, 1880-1940. El sector naval y la industria conservera, Tesis doctoral, Universidad de Santiago.

- (1998): «El caso del asentamiento de la fábrica de conservas de pescado de la empresa Masso en las dos últimas décadas del siglo pasado», en I Encuentro de Económica Aplicada, Barcelona, junio de 1998.

BarRón GARCiA, J. I. (1992): La economía de Cantabria en la etapa de la Restauración, 1875-1908, Santander, Librería Estudio.

Bulletin des Metieres Grasses (1930): «Le marché des Huiles d'olive en Norvège», núm. 8 , pp. 253-254. 
Carmona Badia, Xoan (1983): Producción textil rural e actividades marítimo-pesqueiras na Galiza, 1750-1905, Tesis doctoral, Universidad de Santiago.

- (1985): «La industria conservera gallega. 1840-1905», en Papeles de Economía Española, pp. 177-191.

- (1990): «Crisis y transformación de la base industrial gallega, 1850-1936», en Jordi Nadal y Jordi Catalán, Pautas regionales de la industrialización española (Siglos XIX y XX), Barcelona, Ariel, pp. 35-39.

- (1994): «Recursos, organización y tecnología en el crecimiento de la industria española de conservas de pescado, 1900-1936», en Jordi NADAL y Jordi CATALÁN (eds.), La cara oculta de la industrialización española. La modernización de los sectores no lideres (siglo XIX y XX), Madrid, Alianza, pp. 127-162.

CaStejón Montijano, Rafael (1977): Génesis y desarrollo de una sociedad mercantil $e$ industrial en Andalucia: La casa Carbonell de Córdoba (1866-1918), Córdoba, Caja de Ahorros de Córdoba.

Castejón MontiJano, Rafael, y otros (1980): «Empresas y empresarios andaluces en el siglo XIX: una primera aproximación», en Cuadernos de Ciencias Económicas y Empresariales, núm. 6, pp. 225-256.

Casamada (1935): Memoria de l'Academia de Ciencias y Arts, Barcelona, XXV, núm. 9.

Decrorx, Jean-Louis (1964): Le developpement de l'industrie française de la conserve, Paris, Editions Cujas.

D'Avigneu (1958): L'industrie des conserves de poisson en France metropolitaine, Rennes.

Eichengreen, G., e IrWTn, D. (1996): «The Role of History in Biateral Trade Flows», en NBER, Working Paper, núm. 5.565.

FEAOE (1927): «Disposiciones sobre la determinación de la pureza del aceite de oliva», Informe núm. 203, 22 de noviembre.

Federico, Giovanni (1992): «El comercio exterior de los países mediterráneos en el siglo XIX», en Leandro PRADOS y Vera ZAMAGNI, El desarrollo económico en la Europa del Sur: España e Italia en perspectiva bistórica, Madrid, Alianza, pp. 269-292.

Gallego, Domingo, y Pinilla, Vicente (1996): «Del librecambio matizado al proteccionismo selectivo», en Revista de Historia Económica, año XIV, núm. 2, pp. 372-420.

GAYA, Miguel (1930): «El aceite de oliva en Cataluña», en La industria aceitera, núm. 29, p. 11.

GARRABOU, Ramón, y SANZ, Jesús (1985): «La agricultura española durante el siglo XIX: cinmovilismo o cambio?», en Ramón Garrabou y Jesús Sanz, Historia agraria de la España contemporánea, 2, Expansión y crisis (1850-1900), Barcelona, Ariel, pp. 7-191.

GEHR (1981): Los precios del aceite de oliva en España, 1891-1916, Madrid, Banco de España.

- (1988): «La crisis agrícola en Castilla la Vieja y Andalucía: los casos del trigo y el olivar», en Ramón GARRABOU (ed.), La crisis agraria de fines del siglo XIX, Barcelona, Crítica, pp. 35-68. 
GouLD, D. M. (1994): «Inmigran Links to the Home Country: Empirical Implications for US Bilateral Trade Flows», en Review of Economics and Statistics, núm. 76, pp. 302-316.

HaNN, W. S. (1949): «Observations on Fishprocessing in Norway», en Canner. Citado en Industria conservera, marzo, pp. 16-17.

HERNÁNDEZ ARMENTEROS, Salvador (1997): El crecimiento económico en una región atrasada. Jaén, 1850-1936, Tesis doctoral, Universidad de Granada.

- (1999a): «Viaje a la industria aceitera. La visita del noruego E. Mathiesen a las regiones aceiteras españolas en 1933», en Revista de Estudios Regionales, núm. 55, pp. 299-316.

- (1999b): «La búsqueda de la comercialización en el sector aceitero jiennense: la «Cooperativa Nacional de Productores de Aceite de Oliva Puro», en Actas I Congreso de Cooperativismo Español, Osuna, Fundación Fernando Garrido Tortosa, pp. 163-198.

Higuerta, La (1928): Semanario de Isla Cristina, 10 de septiembre.

HIIDEBRAND, Karl-Gustaf (1981): «Los rasgos característicos de la industrialización de los países escandinavos y de Finlandia en el siglo $\mathrm{XIX}_{\star}$, en VVAA, La industrialización europea. Estadios y tipos, Barcelona, Crítica, pp. 293-303.

HODNE, Fritz (1981): Norges Okonomiske bistoire 1815-1970, Oslo, Cappelen.

INDUSTRIA ConSERVERA (1947): «Las conservas de pescado en Noruega», octubre-noviembre, p. 10.

Industria NaCional, LA (1908): «Relaciones comerciales con Noruega», pp. 179.180 .

JACOBSSEN, Niels (1953): «Situación de la economía noruega durante 1952», en Boletin mensual de la Cámara de Comercio Hispano-Noruega, núm. 3, pp. 5-9.

Jiménez BlanCO, José Ignacio (1986): La producción agraria en Andalucia Oriental, 18741914, Madrid, Universidad Complutense.

LinNEmann, Han (1966): An Econometric Study of International Trade Flows, Amsterdam, North-Holland.

LUNDE, Gulbrand (1933): «Om olivenolje. V. Om pávisning av raffinert olivenolje og sulfurolje ved fluorescensmálinger», en Tidsskrift for bermetikindustri, abril, pp. 112-117.

LUNDE, Gulbrand, y MATHIESEN, Erling (1932): «II. Undersokelse av importet olivenolje av hosten 1929-30 og 1930-31», en Tidsskrift for bermetikindustri, marzo, pp. 81-88.

- (1932): «II. Undersokelse av importet olivenolje av hosten 1931-1932», en Tidsskrift for hermetikindustri, septiembre, pp. 280-282.

LundE, Gulbrand; MATH IIESEN, Erling, y MikKELSEN, Erling (1933): «Om olivenolje. VI. Undersokelse av importert olivenolje av hosten 1932-33», en Tidsskrift for hermetikindustri, diciembre, pp. 375-382.

MalDONADO, Javier (1999): «El sector vinícola en Andalucía», en Andalucia a debate. Terceras Jornadas «Industrialización y desindustrialización de Andalucía. Una revisión bistoriograficas, Granada.

MATIIESEN, Erling (1932): «I. Utvinning og undersokelsesmetoder», en Tidsskrift for hermetikindustri, marzo, pp. 71-78.

- (1933): «Studier over olivenolje pa produksjonsstedene i Spania og Frankrike», en Tidsskrift for Hermetikindustri, febrero, pp. 51-58. 
Milward, Alan, y SAUL, S. B. (1979): El desarrollo económico de la Europa continental, Madrid, Tecnos.

NADAL, Jordi (1987): «La industria fabril española en 1900. Una aproximación», en Jordi NADAL, Albert Carreras y Carles Sudrià, La economia española en el siglo XX. Una perspectiva bistórica, Barcelona, Ariel, pp. 23-61.

Parejo, Antonio, y Zambrana, Juan Francisco (1994): «La modernización de la industria del aceite en España en los siglos XIX y XX», en Jordi NADAL y Jordi Catalan, la cara oculta de la industrialización española, Madrid, Alianza, pp. 13-42.

Pereira, Enrique (1943): «La evolución de una gran industria», en Industria conservera, agosto, pp. 8-9.

Peter, W. (1927): «Medio analítico para diferenciar entre los aceites regenerados según la perfección de su elaboración; y mezcla de éstos con los aceites naturales genuinos», en Boletin mensual de olivicultura, mayo, pp. 721-726.

PinIlLA, Vicente (1995): «Cambio agrario y comercio exterior en la España contemporánea», en Agricultura y Sociedad, núm. 75, pp. 153-179.

POllaro, Sidney (1991): La conquista pacífica. La industrialización de Europa (1760-1970), Zaragoza, Universidad de Zaragoza.

Poggio, Francisco, y MARTin, María (1949): «Espectro de absorción de los aceites de oliva en la zona ultravioleta», en Boletín del Instituto Español de Oceanografía, núm. 14, pp. 1-11.

Prados, Leandro (1982): Comercio exterior y crecimiento económico en España, 1826-1931: tendencias a largo plazo, Madrid, Banco de España.

- (1988): De imperio a nación. Crecimiento y atraso económico en España (1780-1930), Madrid, Alianza.

- (1991): «El comercio exterior y la economía española durante el siglo XIX», en Nicolás SÁNCHEZ AlBORNOZ (comp.), La modernización económica de España, 1830-1930, Madrid, Alianza, pp. 147-175.

Prados, Leandro, y TORTELlA, Gabriel (1983): «Tendencia a largo plazo del comercio exterior español, 1714-1913», en Revista de Historia Económica, año I, núm. 2, pp. 353-376.

RAMÓN MuNoz, Ramón (1997): «La industria aceitera española y los mercados exteriores: un análisis comparativo, 1852-1913», en Actas del II encuentro de Historia Económica, Valencia, UIMP, t. III, pp. 34-65.

- (1998): «Estructura empresarial, empreses i canvi tècni en la indústria de l'oli d'oliva de les comarques de Lleida, 1890-1936», inédito.

- (2000): «Specialization in the international market for olive oil before World War I», en S. Pamuk y J. Williamson (eds.), The Mediterranean Response to Globalization Before 1950, Londres, Routledge, pp. 159-197.

Rios, Segundo (1999): «La industria conservera de Ayamonte: desde sus origenes hasta la II República», en Antonio PAREjo y Andrés Sánchez Picón (eds.), Economia andaluza e bistoria industrial. Estudios en bomenaje a Jordi Nadal, Almería, Azukaria, pp. 657-673.

Romero Atela, Teresa: (1996), «Los empresarios catalanes en Córdoba, 1800-1914», en Els catalans a Espanya, 1760-1914, Barcelona.

Savastano, G., y Serinaco, E. (1935): «Di alcuni procesi moderni di raffinazione», en L'Olivicultore, núm. 8, pp. 3-16. 
SENNER, P. (1943): «La industria de conservas en Noruega», en Industria conservera, octubre, pp. 4.5.

SIERrA, María (1992): La familia Ybarra, empresarios y politicos, Sevilla, Muñoz Moya y Montraveta editores.

SimPSON, James (1992): «Los límites del crecimiento agrario: España, 1860-1936», en Leandro Prados y Vera Zamagni (eds.), El desarróllo económico en la Europa del Sur: España e Italia en perspectiva bistórica, Madrid, Alianza, pp. 103-138.

- (1997): La agricultura española (1765-1965): la larga siesta, Madrid, Alianza.

TENA, A. (1992): «Protección y competitividad en España e Italia, 1890-1960», en Leandro Prados y Vera Zamagni (eds.), El desarrollo económico en la Europa del Sur: España e Italia en perspectiva bistórica, Madrid, Alianza, pp. 321-355.

ZambranA, Juan Francisco (1984): «El aceite de oliva y su dependencia del mercado internacional de las grasas vegetales. Un análisis histórico, 1861-1935», en Agricultura y Sociedad, núm. 33, pp. 159-196.

- (1987): Crisis y modernización del olivar español, Madrid, MAPA.

- (1999): «La industria del aceite de oliva en Andalucía durante el primer franquismo», en Antonio Parejo y Andrés SÁnchez PICón (eds.), Economía andaluza e bistoria industrial. Estudios en bomenaje a Jordi Nadal, Almería, Azukaria, pp. 441-463.

Santiago ZAPATA (1986): La producción agraria en Extremadura y Andalucia Occidental, Madrid, Universidad Complutense. 